\title{
Early relapse rate determines further relapse risk: results of a 5-year follow-up study on pediatric CFH-Ab HUS
}

\author{
Johannes Hofer 1,2,3 - Magdalena Riedl Khursigara ${ }^{3,4} \cdot$ Markus Perl $^{5} \cdot$ Thomas Giner $^{3}$ - Alejandra Rosales ${ }^{3}$. \\ Gerard Cortina $^{3} \cdot$ Siegfied Waldegger ${ }^{3} \cdot$ Therese Jungraithmayr $^{3,6} \cdot$ Reinhard Würzner $^{7}$
}

Received: 20 February 2020 / Revised: 19 July 2020 / Accepted: 31 August 2020 / Published online: 7 October 2020

(C) The Author(s) 2020

\begin{abstract}
Background The complement factor $\mathrm{H}$ antibody (CFH-Ab)-associated hemolytic uremic syndrome (HUS) forms a distinct subgroup within the complement-mediated HUS disease spectrum. The autoimmune nature of this HUS subgroup implies the potential benefit of a targeted immunosuppressive therapy. Data on long-term outcome are scarce.

Methods This observational study evaluates the clinical outcome of 19 pediatric CFH-Ab HUS patients from disease onset until their 5-year follow-up.

Results All but one relapse occurred during the first 2 years, and patients who had no relapse within the first 6 months were relapse-free until the end of the observation period. Kidney function at disease onset determines long-term kidney function: all individuals with normal kidney function at disease onset had normal kidney function after 5 years, and all patients with reduced kidney function at onset had impaired kidney function at the last follow-up. Level of CFH-Ab titer at disease onset was not correlated with a higher risk of recurrences or worse long-term outcome after 5 years. Resolution of CFH-Ab titers after 5 years was common.

Conclusions CFH-Ab HUS patients have a varied overall long-term course. Early relapses are common, making close surveillance during the first years essential, regardless of the initial CFH-Ab titer.
\end{abstract}

Keywords $\mathrm{CFH}-\mathrm{Ab} \cdot$ Hemolytic uremic syndrome $\cdot$ Immunosuppressive therapy

Johannes Hofer

Johannes.Hofer@bblinz.at

Reinhard Würzner

reinhard.wuerzner@i-med.ac.at

1 Institute of Neurology of Senses and Language, Hospital of St John of God, Linz, Austria

2 Research Institute of Developmental Medicine, Johannes Kepler University Linz, Linz, Austria

3 Department of Pediatrics I, Medical University of Innsbruck, Innsbruck, Austria

4 Department of Pediatrics, The Hospital for Sick Children, University of Toronto, Toronto, Ontario, Canada

5 Department of Pediatrics III, Medical University of Innsbruck, Innsbruck, Austria

6 Department of Pediatric Nephrology, Hospital Memmingen, Memmingen, Germany

7 Institute of Hygiene \& Medical Microbiology, Medical University of Innsbruck, Innsbruck, Austria

\section{Introduction}

Complement factor $\mathrm{H}$ antibody (CFH-Ab)-associated hemolytic uremic syndrome (HUS) forms a distinct subgroup of primarily complement-mediated thrombotic microangiopathies (TMA). CFH-Ab-associated HUS is reported in 6-25\% of atypical HUS (aHUS) patients with pediatric onset of the disease [1-4]. Colleagues in India reported a much higher incidence (56\%), which is so far not understood [5].

TMA is characterized by endothelial cell activation and secondary thrombus formation in the microvasculature, resulting in thrombocytopenia, hemolytic anemia, and organ failure. In some cases, endothelial cell activation is a result of complement deposition on the endothelial cell surface due to dysfunctional regulation. In $\mathrm{CFH}-\mathrm{Ab}$-associated HUS, complement dysregulation is caused by antibodies that decrease the function of the major complement regulator CFH [6].

It is generally accepted that early diagnosis of $\mathrm{CFH}-\mathrm{Ab}$ HUS and its distinction from other TMA forms is highly 
important as the autoimmune nature of this TMA implies the potential benefit of targeted immunosuppressive (IS) therapy $[6,7]$. Although no randomized controlled study on the efficacy of a therapy for CFH-Ab HUS is available, a consensus report [7] proposes the following approach for $\mathrm{CFH}-\mathrm{Ab}$ HUS: therapy initiation with eculizumab or plasmapheresis (PP) within the first 2 days of HUS onset. Initiation of IS induction therapy should be based on the severity of extrarenal manifestations and followed by maintenance therapy with mycophenolate mofetil (MMF) and corticosteroids for at least 1 year. However, specifics on which immunosuppressive drug to use as well as the decision to use either eculizumab and/or $\mathrm{PP}$ remains an individual and empirical decision for each physician.

The aim of this observational study was to establish better knowledge on the long-term outcome of patients with pediatric onset $\mathrm{CFH}-\mathrm{Ab}$ HUS.

\section{Methods}

\section{Participants}

Patient data were collected both prospectively and retrospectively by the Austrian-German-HUS-NET study group in cooperation with several participating centers (www.hus-online. at). Only CFH-Ab-positive patients with disease onset $<$ 18 years were included in the study.

Informed consent was given by the patients or their guardians, and the study was performed according to the Declaration of Helsinki (2000), with approval of the local ethics board (Medical University of Innsbruck, Austria). The study includes data from 2002 to 2016. Data were collected from every patient at four times: initial diagnosis and 1, 2, and 5 years after diagnosis. Standardized questionnaires were used. Completed sets of questionnaires from 19 patients, serum samples from the acute phase and all follow-up examinations from 9 patients, and additional serum samples from all other included patients were analyzed.

All patients presented with the criteria for diagnosis of HUS: hemolytic anemia, thrombocytopenia, and kidney dysfunction. Kidney dysfunction was defined by serum creatinine levels greater than normal values according to age and/or urine protein-to-creatinine ratio $>0.2 \mathrm{~g} / \mathrm{g}$.

Relapse was defined by recurrence of hemolytic anemia and/or thrombocytopenia and/or kidney dysfunction at least 2 weeks after a patient has gone into either complete (no signs of hemolytic anemia or thrombocytopenia and normal kidney function) or partial remission (no signs of hemolytic anemia or thrombocytopenia but chronic kidney disease (CKD) and/or proteinuria).

\section{CFH-Ab assessment}

$\mathrm{CFH}-\mathrm{Ab}$ titers were determined using ELISA as previously published [1, 3]. However, due to the fact that disease onset in some patients was prior to 2005 , the year when CFH antibodies were first described [4], initial titers are missing for some patients.

\section{Statistical analyses}

Data were calculated using IBM-SPSS version 22 and Microsoft Excel. Comparison of metric variables was conducted by independent $t$ test for normally and MannWhitney $U$ test for non-normally distributed metric variables; Shapiro-Wilk test was used to test for normal distribution. Comparison of nominal variables was conducted by Fisher's exact test. For the comparison of more than two groups, Kruskal-Wallis test was used for metric scale and Fisher's exact test was used for nominal scale. Dependency was determined either by Pearson's correlation coefficient $(r)$ or by Spearman's rho $\left(r_{s}\right)$. A significance level of 0.05 was applied.

\section{Results}

\section{Patients show continued markers of TMA and kidney dysfunction beyond the acute phase}

Data sets of 19 CFH-Ab HUS patients ( 8 female and 11 male) were analyzed for this study. Mean age at disease onset was $7.7 \pm 2.7$ years (range: $3.5-12.75$ ). Table 1 lists clinical disease manifestations and the main laboratory data at disease onset and during 5-year follow-up. Elevated lactate dehydrogenase (LDH), low C3 levels, and kidney dysfunction continued to be abnormal beyond the acute phase.

Kidney function improved over time; mean eGFR was $82.3 \mathrm{ml} / \mathrm{min} / 1.73 \mathrm{~m}^{2}$ at 1 -year follow-up and $105.3 \mathrm{ml} / \mathrm{min} /$ $1.73 \mathrm{~m}^{2}$ after 5 years. Two patients were excluded from this analysis as they underwent kidney transplantation $[8,9]$.

Interestingly, $\mathrm{LDH}$ continued to be elevated in $67 \%$ at 1-year follow-up, thereafter in $27 \%$ and $11 \%$ at 2- and 5year follow-up, respectively. Decreased C3 levels were still found in $67 \%$ of the patients 1 year after diagnosis; this percentage decreased significantly thereafter. On the other hand, most of the patients $(n=11)$ showed normal platelet counts and hemoglobin levels above $10.0 \mathrm{~g} / \mathrm{dl}$ at all times.

Mean CFH-Ab titer levels decreased over time and were considered normal in two patients at 2 years and ten patients $(55 \%)$ at 5 years after disease onset. 
Table 1 Clinical symptoms and laboratory findings

\begin{tabular}{|c|c|c|c|c|}
\hline & Initial & 1st year & 2nd year & 5 th year \\
\hline Clinical symptoms & $19 / 19$ & $17 / 19$ & $16 / 19$ & $16 / 18$ \\
\hline Arterial hypertension & $72 \%(13 / 18)$ & $74 \%(14 / 19)$ & $79 \%(15 / 19)$ & $83 \%(15 / 18)$ \\
\hline Hematuria & $75 \%(6 / 8)$ & $40 \%(6 / 15)$ & $38 \%(5 / 13)$ & $21 \%(3 / 14)$ \\
\hline Proteinuria & $75 \%(6 / 8)$ & $78 \%(14 / 18)$ & $73 \%(11 / 15)$ & $44 \%(7 / 16)$ \\
\hline Reduced kidney function & $68 \%(13 / 19)$ & $58 \%(11 / 19)$ & $53 \%(10 / 19)$ & $28 \%(5 / 18)$ \\
\hline Abnormal kidney ultrasound & N/A & $62 \%(5 / 8)$ & $50 \%(4 / 8)$ & $56 \%(5 / 9)$ \\
\hline Abnormal ABPM & N/A & $40 \%(2 / 5)$ & $60 \%(3 / 5)$ & $50 \%(2 / 4)$ \\
\hline Extrarenal manifestation & $58 \%(11 / 19)$ & $21 \%(4 / 19)$ & $5 \%(1 / 19)$ & $11 \%(2 / 18)$ \\
\hline \multicolumn{5}{|l|}{ Laboratory examinations } \\
\hline \multirow[t]{3}{*}{ Minimum hemoglobin, $\mathrm{g} / \mathrm{dL}$} & $5.7 \pm 1.1$ & $11.9 \pm 2.4$ & $12.3 \pm 1.6$ & $12.7 \pm 1.8$ \\
\hline & $(5.0-6.6)$ & $(10.8-13.7)$ & $(11.4-13.2)$ & $(12.3-13.8)$ \\
\hline & $(N=18)$ & $(N=15)$ & $(N=18)$ & $(N=18)$ \\
\hline Elevated LDH* & $100 \%(17 / 17)$ & $67 \%(6 / 9)$ & $27 \%(3 / 11)$ & $11 \%(1 / 9)$ \\
\hline Decreased haptoglobin* & $88 \%(7 / 8)$ & $40 \%(2 / 5)$ & $60 \%(3 / 5)$ & $0 \%(0 / 4)$ \\
\hline \multirow[t]{3}{*}{ Minimum platelets, $10^{9} / \mathrm{L}$} & $29 \pm 12$ & $265 \pm 94$ & $269 \pm 65$ & $278 \pm 72$ \\
\hline & $(21-35)$ & $(193-347)$ & $(214-312)$ & $(231-332)$ \\
\hline & $(N=17)$ & $(N=14)$ & $(N=18)$ & $(N=18)$ \\
\hline \multirow[t]{3}{*}{ Maximum creatinine, $\mu \mathrm{mol} / \mathrm{L}$} & $390 \pm 280$ & $222 \pm 311$ & $217 \pm 319$ & $145 \pm 236$ \\
\hline & $(196-500)$ & $(67-188)$ & $(54-94)$ & $(56-78)$ \\
\hline & $(N=17)$ & $(N=18)$ & $(N=19)$ & $(N=18)$ \\
\hline \multirow[t]{3}{*}{ eGFR, $\mathrm{ml} / \mathrm{min} / 1.73 \mathrm{~m}^{2}$} & $75 \pm 56$ & $82 \pm 44$ & $87 \pm 45$ & $105 \pm 25$ \\
\hline & $(12-132)$ & $(51-118)$ & $(68-121)$ & $(80-125)$ \\
\hline & $(N=8)$ & $(N=13)$ & $(N=13)$ & $(N=11)^{\#}$ \\
\hline \multirow[t]{4}{*}{$\mathrm{CFH}-\mathrm{Ab}$ titer, $\mathrm{AU} / \mathrm{ml}$} & $1533 \pm 481$ & $604 \pm 375$ & $<100(N=2)$ & $<100(N=10)$ \\
\hline & $(959-1933)$ & $(368-809)$ & $461 \pm 224$ & $290 \pm 142$ \\
\hline & & & $(264-650)$ & $(135-394)$ \\
\hline & $(N=10)$ & $(N=14)$ & $(N=15)$ & $(N=8)$ \\
\hline \multirow[t]{3}{*}{ C3 level, mg/dL } & $76 \pm 29$ & $93 \pm 27$ & $87 \pm 18$ & $100 \pm 17$ \\
\hline & $(56-95)$ & $(67-110)$ & $(69-101)$ & $(82-118)$ \\
\hline & $(N=16)$ & $(N=12)$ & $(N=12)$ & $(N=10)$ \\
\hline Low C3 level* & $65 \%(11 / 17)$ & $67 \%(6 / 9)$ & $33 \%(3 / 9)$ & $13 \%(1 / 8)$ \\
\hline \multirow[t]{3}{*}{ C4 level, mg/dL } & $21 \pm 9.7$ & $26 \pm 16$ & $21 \pm 7.5$ & $23 \pm 12$ \\
\hline & $(12-24)$ & $(13-34)$ & $(17-24)$ & $(13-30)$ \\
\hline & $(N=12)$ & $(N=11)$ & $(N=10)$ & $(N=9)$ \\
\hline Low C4 level* & $14 \%(2 / 14)$ & $14 \%(1 / 7)$ & $0 \%(0 / 6)$ & $0 \%(0 / 6)$ \\
\hline
\end{tabular}

The number of evaluable answers is indicated in parentheses $(N)$. Data is presented as absolute number of cases per number of evaluable patients $(n / N)$ or as mean \pm standard deviation (interquartile range)

$C N S$ central nervous system, $L D H$ lactate dehydrogenase, $e G F R$ estimated glomerular filtration rate calculated with the Schwartz formula

*According to local references used by the respective laboratory, which was unavailable in several cases

\# Excluding the two patients who underwent renal transplantation

\section{Extrarenal manifestations are common in CFH-Ab patients}

Extrarenal manifestations at disease onset were documented for 10 patients (Table 2) and mainly involved gastrointestinal symptoms such as diarrhea and vomiting. At 1-year follow- up, four patients showed extrarenal involvement. At the 2year follow-up, only one case of extrarenal complication was found (patient 19 still had dilated aorta); however, at the 5-year follow-up, extrarenal involvement was found in two patients (in patient 19 with the dilated aorta, and in patient 6 , who had no previous extrarenal symptoms, left ventricular 
Table 2 Extrarenal complications during the 5-year follow-up period

\begin{tabular}{|l|l|l|l|l|}
\hline ID & Initial & 1st year & 2nd year & 5th year \\
\hline 1 & Cyclic vomiting, abdominal pain, & Hypertensive encephalopathy & / & \\
\hline 2 & Cyclic vomiting, abdominal pain, diarrhea & Tonic-clonic seizures & Tonic-clonic seizures & Tonic-clonic seizures \\
\hline 4 & $\begin{array}{l}\text { Cholestasis with elevated liver enzymes, } \\
\text { cyclic vomiting, abdominal pain }\end{array}$ & & & \\
\hline 6 & $/$ & & & Left vebtricular hypertrophy \\
\hline 8 & Pancreatitis & $/$ & $\begin{array}{l}\text { Death due to cardiac arrest; } \\
\text { developed cardiomyopathy }\end{array}$ & \\
\hline 11 & $\begin{array}{l}\text { Elevated liver enzymes, abnormal EEG } \\
\text { without detectable seizures }\end{array}$ & & & \\
\hline 12 & Cyclic vomiting, abdominal pain & & & \\
\hline 13 & Cyclic vomiting, hyperbilirubinemia & & & \\
\hline 15 & Abdominal pain, diar-hea & & & $16 \%$ with seizures or encephalopathy with cardiovascular manifestations \\
\hline 16 & $/$ & Epileptic seizures & $/$ & $16 \%$ with extrarenal symptoms at 5 year follow up \\
\hline 18 & Elevated liver enzymes & & & \\
\hline 19 & Cyclic vomiting, abdominal pain, diarrhea & Dilatated aorta & Dilatated aorta & Dilatated aorta \\
\hline
\end{tabular}

hypertrophy was detected in the setting of arterial hypertension). Patient 8 died during the third year after being diagnosed with non-compaction cardiomyopathy. He was on eculizumab therapy for about 1 year before his death. Except for age at disease onset (significantly higher in patients with extrarenal symptoms; $n=19$, Spearman rank correlation coefficient $=0.558, p<0.02$ ), no further significant differences between patients with and without extrarenal complications were found.

\section{Patients with CFH Ab HUS received a variety of treatments}

Initially, 68\% (13/19) of patients required kidney replacement therapy; however at 1- and 2-year follow-up, only $26 \%(n=5)$ of the patients remained on dialysis (Table 3$)$. After 5 years, two out of those five patients were transplanted, another two were still dependent on dialysis, and one patient was started on eculizumab and was able to stop dialysis.

Except for one patient who developed stage 5 CKD directly after the first TMA episode (and who was transplanted thereafter [8]), all other patients received some kind of targeted therapy (plasma therapy (PT) and/or IS) at initial manifestation and 1-year follow-up (Table 3; Fig. 1). At 5-year followup, 9 out of 18 patients were still on $\mathrm{CFH}$-Ab-targeted therapy (Fig. 1).

Eculizumab therapy was initiated in a second patient shortly after the 2-year follow-up and was still administered at the 5-year follow-up. Two years after diagnosis and prior to eculizumab, the patient continues to show signs of hemolysis, his CFH-Ab titer was slightly elevated at $420 \mathrm{AU} / \mathrm{ml}$ and was on chronic dialysis. At 5-year follow-up, the patient had regained sufficient kidney function (eGFR: $76 \mathrm{ml} / \mathrm{min} / 1.73 \mathrm{~m}^{2}$ ) and was able to come off dialysis. Left ventricular hypertrophy was noted on echocardiography.

\section{Relapses are common within the first 6 months of disease onset}

Relapses were common, with fourteen patients (74\%) suffering from at least one relapse (Table 4; Figs. 1 and 2). All patients had their first relapse during the first 6 months after diagnosis; the longest documented period from diagnosis to first relapse was 5.5 months. Only three patients had one or more relapses in the second year, and only one patient had a relapse in the third year (Table 4). The average time to the first relapse was $1.8 \pm 1.3$ months (range: 3 weeks -5.5 months); the average time to the last relapse was $7.8 \pm 8.3$ months (range: 1.8-28.0 months). On average, patients with relapses had $2.3 \pm 1.6$ relapses (range $1-6$ ). Seven patients had only one relapse, 2 patients showed two relapses, 1 patient had 3 relapses, 3 patients showed 4 relapses, and one patient showed 6 relapses.

A significant correlation from timepoint of first relapse to further relapse probability was noted, but no relation to outcome parameters at 5-year follow-up was observed (Table 5). There was no significant difference in any of the clinical or laboratory parameters at disease onset between patients with relapses during the first 6 months $(n=14)$ and those without ( $n=5$; Table 4). Moreover, patients relapsing during the first 6 months did not show higher initial CFH-Ab titers.

A steady decrease of available CFH-Ab titers from disease onset up to 5-year follow-up was observed (Fig. 3).

The available data on symptoms and therapy during relapses are incomplete. In all evaluable events (10 relapses of seven individual patients), patients presented with proteinuria and reduced kidney function during the relapse, and plasma therapy was first-line treatment. 
Table 3 Therapy at disease onset and during follow-up

\begin{tabular}{|c|c|c|c|c|}
\hline & Initial & 1st year & 2nd year & 5 th year \\
\hline \multicolumn{5}{|l|}{ Kidney replacement therapy } \\
\hline Dialysis & $68 \%(13 / 19)$ & $26 \%(5 / 19)$ & $26 \%(5 / 19)$ & $11 \%(2 / 18)$ \\
\hline Transplanted & $0 \%(0 / 19)$ & $0 \%(0 / 19)$ & $0 \%(0 / 19)$ & $11 \%(2 / 18)$ \\
\hline \multicolumn{5}{|l|}{ TMA-specific therapy } \\
\hline Plasma therapy & $95 \%(18 / 19)$ & $53 \%(10 / 19)$ & $26 \%(5 / 19)$ & $6 \%(1 / 18)$ \\
\hline Plasma infusion & $16 \%(3 / 19)$ & $21 \%(4 / 19)$ & $11 \%(2 / 19)$ & $0 \%(0 / 18)$ \\
\hline Plasmapheresis & $32 \%(6 / 19)$ & $26 \%(5 / 19)$ & $16 \%(3 / 19)$ & $6 \%(1 / 18)$ \\
\hline Both & $47 \%(9 / 19)$ & $5 \%(1 / 19)$ & $0 \%(0 / 19)$ & $0 \%(0 / 18)$ \\
\hline Immunosuppressive/-modulatory therapy & $16 \%(3 / 19)$ & $42 \%(8 / 19)$ & $37 \%(7 / 19)$ & $44 \%(8 / 18)$ \\
\hline Steroids & $16 \%(3 / 19)$ & $21 \%(4 / 19)$ & $5 \%(1 / 19)$ & $11 \%(2 / 18)$ \\
\hline Mycophenolate mofetil & $0 \%(0 / 19)$ & $21 \%(4 / 19)$ & $32 \%(6 / 19)$ & $33 \%(6 / 18)$ \\
\hline Rituximab & $0 \%(0 / 19)$ & $21 \%(4 / 19)$ & $11 \%(2 / 19)$ & $0 \%(0 / 18)$ \\
\hline IV immunoglobulins & $0 \%(0 / 19)$ & $16 \%(3 / 19)$ & $0 \%(0 / 19)$ & $11 \%(2 / 18)$ \\
\hline \multicolumn{5}{|l|}{ Biologicals } \\
\hline Eculizumab & $0 \%(0 / 19)$ & $0 \%(0 / 19)$ & $5 \%(1 / 19)$ & $6 \%(1 / 18)$ \\
\hline \multicolumn{5}{|l|}{ Therapy of sequelae } \\
\hline Antihypertensive drugs & $47 \%(9 / 19)$ & $74 \%(14 / 19)$ & $79 \%(15 / 19)$ & $83 \%(15 / 18)$ \\
\hline Diuretics & $32 \%(6 / 19)$ & $32 \%(6 / 19)$ & $21 \%(4 / 19)$ & $28 \%(5 / 18)$ \\
\hline Antiepileptics & $0 \%(0 / 19)$ & $0 \%(0 / 19)$ & $5 \%(1 / 19)$ & $6 \%(1 / 18)$ \\
\hline Other drugs & $26 \%(5 / 19)$ & $16 \%(3 / 19)$ & $21 \%(4 / 19)$ & $22 \%(4 / 18)$ \\
\hline Packed RBC & $84 \%(16 / 19)$ & $0 \%(0 / 19)$ & $0 \%(0 / 19)$ & $0 \%(0 / 18)$ \\
\hline Platelet transfusion & $21 \%(4 / 19)$ & $0 \%(0 / 19)$ & $0 \%(0 / 19)$ & $0 \%(0 / 18)$ \\
\hline Antiplatelet drugs & $5 \%(1 / 19)$ & $0 \%(0 / 19)$ & $0 \%(0 / 19)$ & $0 \%(0 / 18)$ \\
\hline Heparin & $11 \%(2 / 19)$ & $0 \%(0 / 19)$ & $0 \%(0 / 19)$ & $0 \%(0 / 18)$ \\
\hline No therapy & $0 \%(0 / 19)$ & $16 \%(3 / 19)$ & $21 \%(4 / 19)$ & $17 \%(3 / 18)$ \\
\hline
\end{tabular}

Data is presented as absolute number of cases per number of evaluable patients $(n / N)$

\section{Three quarters of patients are in complete or partial remission after 5 years}

Eighteen patients (95\%) were alive at the 5-year followup (Fig. 1). Thirty-two percent $(n=6)$ were in complete remission, four of those showing arterial hypertension and two still with detectable CFH-Abs. Partial remission was observed in $42 \%(n=8)$, including 7 with arterial hypertension and 5 with detectable $\mathrm{CFH}-\mathrm{Abs}$. Including the patient who died during the third year, $26 \%(n=5)$ presented with CKD 5 (one of those with still detectable CFH-Abs) during follow-up.

Altogether, 5 years post initial manifestation, $68 \%(n=13)$ showed a normal eGFR (two of those transplanted), eight of them with some signs of kidney damage in the form of proteinuria, hematuria, or pathological findings on kidney ultrasound.

All patients with impaired kidney function at the 5-year follow-up already presented with reduced kidney function at initial manifestation. Patients with normal kidney function at initial manifestation still had so after 5 years.
Fifteen patients had arterial hypertension at the 5-year follow-up. Of the 13 patients with high blood pressure at the initial manifestation, only one recovered and regained normal blood pressure after 2 years. Five patients developed arterial hypertension at any point in follow-up. An analysis of the patient's initial characteristics, laboratory findings, and therapy in regard to their outcome after 5 years (i.e. complete remission, partial remission, CKD 5, or death) showed no statistically significant differences between the groups.

\section{Discussion}

This study evaluates the clinical outcome of $19 \mathrm{CFH}-\mathrm{Ab}-$ positive pediatric HUS patients from disease onset over a 5year follow-up period, making it the longest pediatric followup study of CFH-Ab-positive patients.

In general, relapses are common in CFH-Ab aHUS patients. Dragon-Durey et al. reported relapses in 25 of $44 \mathrm{CFH}-\mathrm{Ab}$ HUS patients, whereof 17 had their first relapse within 6 months from onset; however, in five patients, a relapse was seen after 


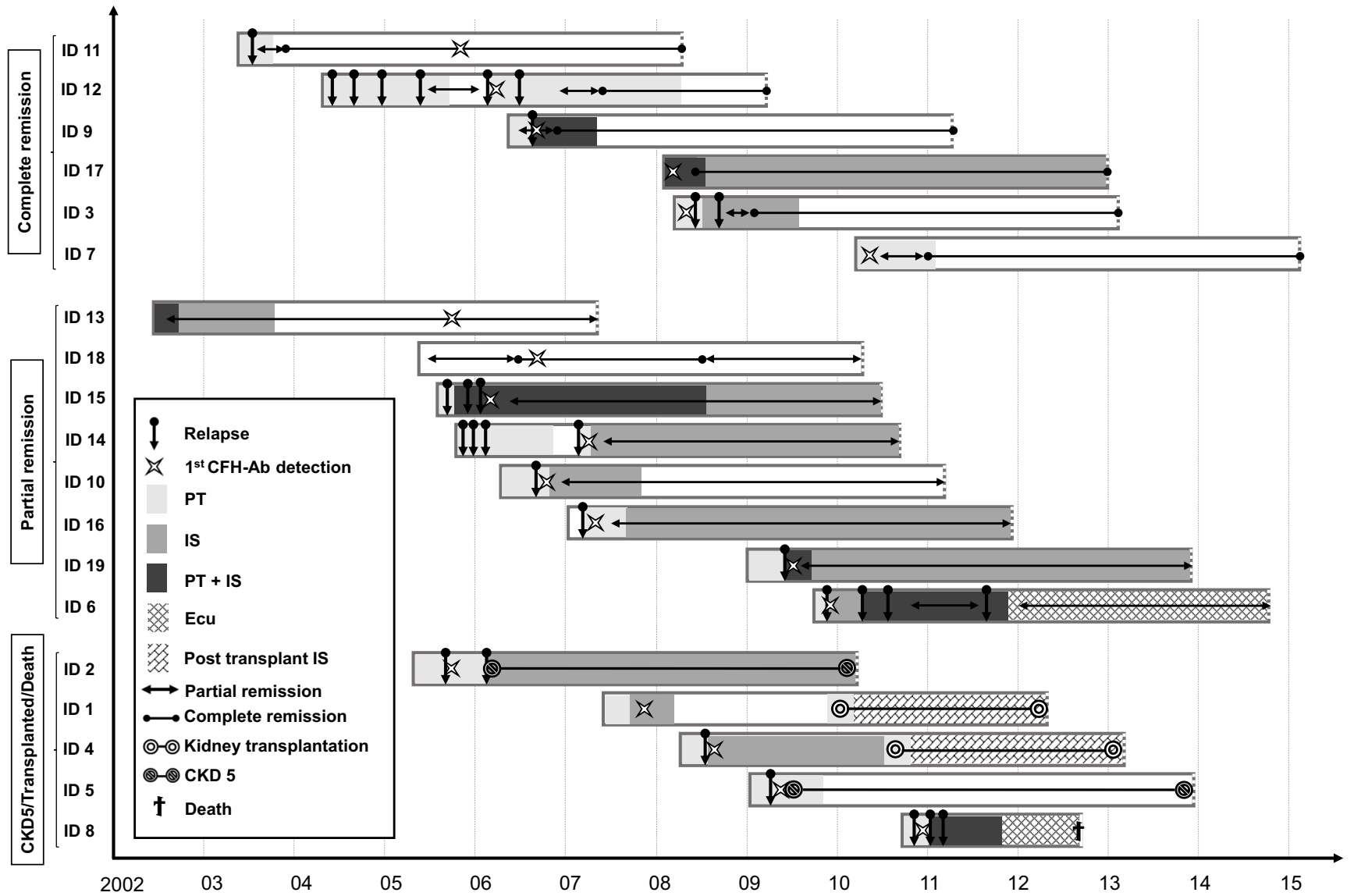

Fig. 1 Swimmer plot grouped according to the outcome. The outcome after the 5-year follow-up period determines the group assignment. In patients $1,3,4,5,7,11,15,16,17$, and $18, \mathrm{CFH}-\mathrm{Ab}$ titers dropped and are negative at 5-year follow-up. In patients 2, 6, 9, 10, 12, 13, 14, and 19, $\mathrm{CFH}-\mathrm{Ab}$ titers are still detectable at 5 -year follow-up but in the low titer range (> 100 and $<600 \mathrm{AU} / \mathrm{ml})$. X-axis: years of observation. Beginning of the bars refers to onset of disease, which was quasi identical to the timepoint of HUS diagnosis (maximum of 2-week difference). Y-axis:

group assignment and patient ID. Complete remission: normalization of LDH, haptoglobin, hemoglobin, and platelets in combination with normal kidney function. Partial remission: normalization of LDH, haptoglobin, hemoglobin, and platelets but presence of chronic kidney disease and/or proteinuria [13]. AU arbitrary units, $\mathrm{CFH}-\mathrm{Ab}$ complement factor $\mathrm{H}$ antibodies, CKD stage 5 chronic kidney disease, Ecu eculizumab, HUS hemolytic uremic syndrome, IS any kind of immunosuppressive therapy except eculizumab, PT plasma therapy (any kind)

more than 12 months [10]. Sinha et al. reported disease relapse in only 14 of 122 patients and argued that this number is comparatively low because of the stringent induction of IS maintenance therapy in their patients [5]. Of the 19 patients described here, relapses were seen in 14 cases. The first relapse for each patient occurred within 6 months from diagnosis, and patients who did not suffer a relapse in the first 6 months were relapsefree until the end of the observation period. These findings emphasize the importance of treatment and close follow-up within the first year. Interestingly, in all sufficiently documented relapses (10 relapses of seven individual patients), proteinuria was described. Ardissino et al. suggested the implementation of urine test strips for home monitoring and early diagnosis of possible relapses in cases of discontinued eculizumab therapy [11]. Based on our data on CFH-Ab patients, screening for proteinuria or change in the severity of proteinuria may serve as a reasonable and economical method to identify relapses even with home-based monitoring.

Table 4 Distribution of relapses over the follow-up period

\begin{tabular}{|c|c|c|c|c|c|}
\hline & $<6 \mathrm{~m}$ & $6<9 \mathrm{~m}$ & $9<12 \mathrm{~m}$ & $12<24 \mathrm{~m}$ & $\geq 24 \mathrm{~m}$ \\
\hline Patients with $\geq 1$ relapse & $n=14$ & $n=2$ & $n=3$ & $n=3$ & $n=1$ \\
\hline Relapses (\% of all relapses) & $21(67.7)$ & $2(6.5)$ & $3(9.7)$ & $4(12.9)$ & $1(3.2)$ \\
\hline Patients with $>1$ relapse & $n=5$ & None & None & $n=1$ & None \\
\hline Range of relapses & $1-3$ & 1 & 1 & $1-2$ & 1 \\
\hline
\end{tabular}




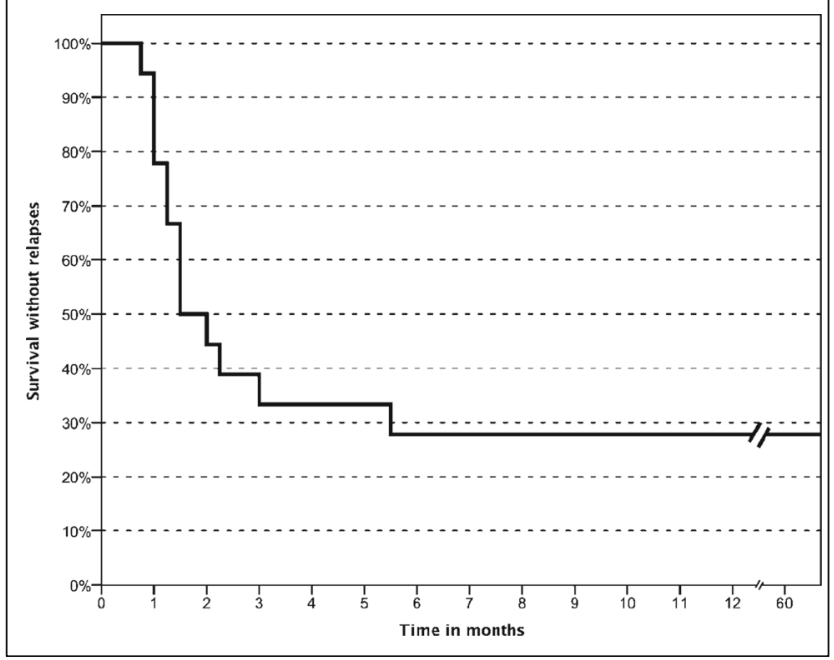

Fig. 2 Relapse-free survival curve. As further detailed in the text, all of the first relapses occurred within the first 6 months after disease onset. One patient is missing as the exact timepoint of the first relapse is not known (but was before 6 months after disease onset)

Overall, there was no connection between higher titers and disease severity noticed. Initial CFH-Ab titer did not serve as a predictor for long-term outcome; however, during relapses, the $\mathrm{CFH}-\mathrm{Ab}$ titer was higher than during remission, thus the individual patient's titer development may serve as potential predictor for relapses.

The occurrence of extrarenal manifestations of TMA is frequent in aHUS patients [12]. In CFH-Ab HUS patients, central nervous system (CNS) involvement has been found in 14 to $41 \%$ of patients $[5,10,13]$. Pancreatitis was found in $23 \%$ [10], and elevated liver enzymes were reported in $50 \%$ [10] and $57 \%$ [5] of the cases. In this study, $63 \%$ of patients were reported with extrarenal involvement. Twenty-one percent had a CNS involvement, $16 \%$ had a cardiovascular involvement, and 58\% had some form of gastrointestinal involvement. For all but one patient, multiple extrarenal manifestations were registered. Of note, all the CNS and gastrointestinal involvements occurred during the initial phase or the first year, whereas the cardiovascular involvements became evident after the first-year follow-up. This might have been

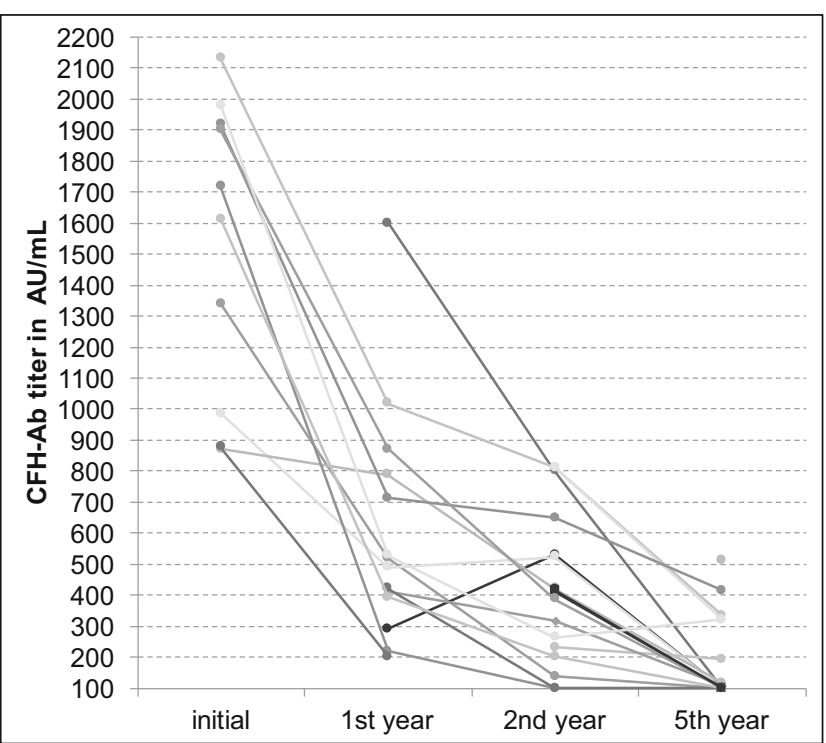

Fig. 3 Evolution of CFH-Ab titers over 5-year follow-up period. Steady decrease of available $\mathrm{CFH}-\mathrm{Ab}$ titers from disease onset up to 5-year follow-up (at 5 years, $55 \%$ of patients with $\mathrm{CFH}$-Ab titers under cut-off of $100 \mathrm{AU} / \mathrm{ml})$

influenced by continuous arterial hypertension resulting in cardiac changes like left ventricular hypertrophy.

Treatment modalities varied greatly between patients and were partly influenced by time of presentation as treatment recommendations evolved over time. Two of the patients were treated with eculizumab during the follow-up period: patient 6 was treated with a combination of PT and IS at the first- and second-year follow-up and received a combination of PT and eculizumab from the third year onwards.

The therapy of patient 8 was changed during the second year from a combination of PT, IS, and intravenous immunoglobulins to eculizumab. He died after almost exactly 1 year on this therapy due to non-compaction myocardiopathy. The efficacy of eculizumab on extrarenal manifestations is a controversial issue - some case reports on successful therapy of extrarenal involvements with eculizumab are available [14-18].

In the literature, the percentage of patients who develop CKD 5 or die ranges from 34 to $63 \%$ [2, 5, 10, 13, 19], partial

Table 5 Statistical relations of patients with and without relapse within the first 6 months

No relapse within 6 months from disease onset

$\geq 1$ relapse within 6 months from disease onset

12

2

$p<0.002$

4

6

4

n.s. $\geq 1$ relapse $>6$ months from disease onset

0

5

Fisher's exact

Complete remission at 5 years

Partial remission at 5 years

$\mathrm{CKD} 5 \mathrm{D} / \mathrm{KT} /$ Death at 5 years

Fisher's exact

220

0.002

2

1

$C K D 5 D$ chronic kidney disease stage 5 treated by dialysis, $K T$ kidney transplant, $n . s$. not significant 
remission ranges from 25 to $83 \%[3,5,10,13,20]$, and complete remission from 0 to $25 \%$ [3, 10, 13, 20]. In the present cohort, $26 \%$ developed CKD 5 or died, $42 \%$ had a partial remission, and $32 \%$ had a complete remission after 5 years. There was no difference in clinical presentation or CFH-Ab titers between patients with favorable or non-favorable outcome.

Impaired kidney function at one of the follow-up appointments was in all cases preceded by reduced kidney function at the initial manifestation. Patients with normal kidney function during the initial phase had normal function at the 5-year follow-up, suggesting that kidney damage mainly occurs at the initial manifestation. Similarly, Geerdink et al. reported arterial hypertension in $67 \%$ of their patients in the long term [3]. In a large prospective long-term follow-up study (German-Austrian HUS-NET) on patients with STEC HUS, it was noted that $18 \%$ developed proteinuria and/or arterial hypertension within the 1and 5-year follow-up. The increasing rate of arterial hypertension over the years supports our recommendation for a close and lifelong monitoring of CFH-Ab HUS patients, especially as nearly no data exists on the evolution of the disease beyond adolescence and early adulthood.

In conclusion, CFH-Ab HUS patients show early relapses and long-term follow-up depends on initial manifestation. Antibody titers do not correlate well with outcome and disappeared in most of our patients within 5 years.

Our findings stress the importance of ongoing surveillance, especially at the initial phase and during the first year regardless of the initial $\mathrm{CFH}-\mathrm{Ab}$ titers, owing to frequent relapses especially during the early period.

Acknowledgments We are thankful to all collaborating medical centers and physicians (listed on www.hus-online.at).

Code availability Not applicable.

Authors' contributions All authors contributed to the study conception and design. Data collection and analysis were performed by Johannes Hofer, Markus Perl, Thomas Giner, Magdalena Riedl Khursigara, Gerard Cortina, and Therese Jungraithmayr. The manuscript was written by Johannes Hofer, Reinhard Würzner, and Magdalena Riedl Khursigara. All authors commented on previous versions of the manuscript. All authors read and approved the final manuscript.

Funding Open access funding provided by Austrian Science Fund (FWF). This study was supported by the European Pediatric Research group for HUS, the Gesellschaft für Pädiatrische Nephroplogie, the Tiroler Wissenschaftsfond, the Österreichische Nationalbank (Grant 12711), and the Austrian Research fund (FWF, HOROS, W1253-B24).

Data availability The datasets analyzed during the current study are available from the corresponding author on reasonable request.

\section{Compliance with ethical standards}

Conflicts of interest J.H., M.R. K., and R.W. have received honoraria from Alexion Pharmaceuticals Inc. and/or unrestricted educational grants and have served on various advisory boards.
Ethics approval Approval was obtained from the ethics committee of the Medical University of Innsbruck, Austria. The procedures used in this study adhere to the tenets of the Declaration of Helsinki.

Consent to participate Informed consent was given by the patients and/ or their guardians.

Consent for publication Included in the general consent form.

Open Access This article is licensed under a Creative Commons Attribution 4.0 International License, which permits use, sharing, adaptation, distribution and reproduction in any medium or format, as long as you give appropriate credit to the original author(s) and the source, provide a link to the Creative Commons licence, and indicate if changes were made. The images or other third party material in this article are included in the article's Creative Commons licence, unless indicated otherwise in a credit line to the material. If material is not included in the article's Creative Commons licence and your intended use is not permitted by statutory regulation or exceeds the permitted use, you will need to obtain permission directly from the copyright holder. To view a copy of this licence, visit http://creativecommons.org/licenses/by/4.0/.

\section{References}

1. Hofer J, Janecke AR, Zimmerhackl LB, Riedl M, Rosales A, Giner T, Cortina G, Haindl CJ, Petzelberger B, Pawlik M, Jeller V, Vester U, Gadner B, van Husen M, Moritz ML, Würzner R, Jungraithmayr T, German-Austrian HUS Study Group (2013) Complement factor $\mathrm{H}$-related protein 1 deficiency and factor $\mathrm{H}$ antibodies in pediatric patients with atypical hemolytic uremic syndrome. Clin J Am Soc Nephrol 8:407-415

2. Moore I, Strain L, Pappworth I, Kavanagh D, Barlow PN, Herbert AP, Schmidt CQ, Staniforth SJ, Holmes LV, Ward R, Morgan L, Goodship TH, Marchbank KJ (2010) Association of factor H autoantibodies with deletions of CFHR1, CFHR3, CFHR4, and with mutations in $\mathrm{CFH}, \mathrm{CFI}, \mathrm{CD} 46$, and $\mathrm{C} 3$ in patients with atypical hemolytic uremic syndrome. Blood 115:379-387

3. Geerdink LM, Westra D, van Wijk JA, Dorresteijn EM, Lilien MR, Davin JC, Kömoff M, Van Hoeck K, van der Vlugt A, van den Heuvel LP, van de Kar NC (2012) Atypical hemolytic uremic syndrome in children: complement mutations and clinical characteristics. Pediatr Nephrol 27:1283-1291

4. Dragon-Durey MA, Loirat C, Cloarec S, Macher MA, Blouin J, Nivet H, Weiss L, Fridman WH, Frémeaux-Bacchi V (2005) Anti-factor $\mathrm{H}$ autoantibodies associated with atypical hemolytic uremic syndrome. J Am Soc Nephrol 16:555-563

5. Sinha A, Gulati A, Saini S, Blanc C, Gupta A, Gurjar BS, Saini H, Kotresh ST, Ali U, Bhatia D, Ohri A, Kumar M, Agarwal I, Gulati S, Anand K, Vijayakumar M, Sinha R, Sethi S, Salmona M, George A, Bal V, Singh G, Dinda AK, Hari P, Rath S, Dragon-Durey MA, Bagga A (2014) Prompt plasma exchanges and immunosuppressive treatment improves the outcomes of anti-factor $\mathrm{H}$ autoantibodyassociated hemolytic uremic syndrome in children. Kidney Int 85: $1151-1160$

6. Hofer J, Giner T, Jozsi M (2014) Complement factor H-antibodyassociated hemolytic uremic syndrome: pathogenesis, clinical presentation, and treatment. Semin Thromb Hemost 40:431-443

7. Loirat C, Fakhouri F, Ariceta G, Besbas N, Bitzan M, Bjerre A, Coppo R, Emma F, Johnson S, Karpman D, Landau D, Langman CB, Lapeyraque AL, Licht C, Nester C, Pecarora C, Riedl M, Van de Kar N, Van de Walle J, Vivarelli M, Frémeaux-Bacchi V (2016) 
An international consensus approach to the management of atypical hemolytic uremic syndrome in children. Pediatr Nephrol 31:15-39

8. Hofer J, Giner T, Cortina G, Jungraithmayr T, Masalskiene J, Dobiliene D, Mitkiene R, Pundziene B, Rudaitis S (2015) Successful living-related renal transplantation in a patient with factor $\mathrm{H}$ antibody-associated atypical hemolytic uremic syndrome. Pediatr Transplant 19:E121-E125

9. Grenda R, Jarmuzek W, Rubik J, Prokurat S, Miklaszewska M, Drozdz D, Zachwieja K, Ardissino G, Hofer J (2015) Favorable 4-year outcome after renal transplantation in a patient with complement factor $\mathrm{h}$ antibody and CFHR1/CFHR3 gene mutation- associated HUS. Pediatr Transplant 19:E130-E134

10. Dragon-Durey MA, Sethi SK, Bagga A, Blanc C, Blouin J, Ranchin B, André JL, Takagi N, Cheong HI, Hari P, Le Quintrec M, Niaudet P, Loirat C, Fridman WH, Frémeaux-Bachi V (2010) Clinical features of anti-factor $\mathrm{H}$ autoantibody-associated hemolytic uremic syndrome. J Am Soc Nephrol 21:2180-2187

11. Ardissino G, Testa S, Possenti I, Tel F, Paglialonga F, Salardi S, Tedeschi S, Belingheri M, Cugno M (2014) Discontinuation of eculizumab maintenance treatment for atypical hemolytic uremic syndrome: a report of 10 cases. Am J Kidney Dis 64:633-637

12. Hofer J, Rosales A, Fischer C, Giner T (2014) Extra-renal manifestations of complement-mediated thrombotic microangiopathies. Front Pediatr 2:97

13. Noris M, Caprioli J, Bresin E, Mossali C, Pianetti G, Gamba S, Daina E, Fenili C, Castelletti F, Sorosina A, Piras R, Donadelli R, Maranta R, van der Meer I, Conway EM, Zipfel PF, Goodship TH, Remuzzi G (2010) Relative role of genetic complement abnormalities in sporadic and familial aHUS and their impact on clinical phenotype. Clin J Am Soc Nephrol 5:1844-1859
14. EMA. European public assessment report summary for the public: Soliris eculizumab. London: European Medicines Agency, 2015

15. Diamante Chiodini B, Davin JC, Corazza F, Khaldi K, Dahan K, Ismaili K, Adams B (2014) Eculizumab in anti-factor h antibodies associated with atypical hemolytic uremic syndrome. Pediatrics 133:e1764-e1768

16. Gulleroglu K, Fidan K, Hançer VS, Bayrakci U, Baskin E, Soylemezoglu O (2013) Neurologic involvement in atypical hemolytic uremic syndrome and successful treatment with eculizumab. Pediatr Nephrol 28:827-830

17. Ardissino G, Tel F, Testa S, Marzano AV, Lazzari R, Salardi S, Edefonti A (2014) Skin involvement in atypical hemolytic uremic syndrome. Am J Kidney Dis 63:652-655

18. Ohanian M, Cable C, Halka K (2011) Eculizumab safely reverses neurologic impairment and eliminates need for dialysis in severe atypical hemolytic uremic syndrome. Clin Pharmacol 3:5-12

19. Abarrategui-Garrido C, Martínez-Barricarte R, López-Trascasa M, de Córdoba SR, Sánchez-Corral P (2009) Characterization of complement factor H-related (CFHR) proteins in plasma reveals novel genetic variations of CFHR1 associated with atypical hemolytic uremic syndrome. Blood 114:4261-4271

20. Song D, Liu XR, Chen Z, Xiao HJ, Ding J, Sun SZ, Liu HY, Guo WY, Wang SX, Yu F, Zhao MH (2017) Chinese Renal-TMA Network Institutes: The clinical and laboratory features of Chinese Han anti-factor $\mathrm{H}$ autoantibody-associated hemolytic uremic syndrome. Pediatr Nephrol 32:811-822

Publisher's note Springer Nature remains neutral with regard to jurisdictional claims in published maps and institutional affiliations. 